\title{
Infants' Reasoning About Others' False Perceptions
}

\author{
Hyun-joo Song \\ Yonsei University
}

\author{
Renée Baillargeon \\ University of Illinois
}

\begin{abstract}
Prior research suggests that children younger than age 3 or 4 do not understand that an agent may be deceived by an object's misleading appearance. The authors asked whether 14.5-month-olds would give evidence in a violation-of-expectation task that they understand that agents may form false perceptions. Infants first watched events in which an agent faced a stuffed skunk and a doll with blue pigtails; the agent consistently reached for the doll, suggesting that she preferred it over the skunk. Next, while the agent was absent, the doll was hidden in a plain box, and the skunk was hidden in a box with a tuft of blue hair protruding from under its lid. Infants expected the agent to be misled by the tuft's resemblance to the doll's hair and to falsely perceive it as belonging to the doll. These and other results indicate that 14.5-month-old infants can already reason about agents' false perceptions.
\end{abstract}

Keywords: infant cognition, action comprehension, psychological reasoning, theory of mind, false perception

Our ability to make sense of others' actions rests in large part on our ability to understand the mental states that underlie these actions. Critical to this understanding is the recognition that mental states sometimes conflict with reality. Thus, we realize that Little Red Riding Hood blithely approaches the wolf lying in wait in her grandmother's bed, dressed in a cap and nightgown, because she is deceived by this disguise and mistakenly perceives the wolf as her grandmother. Here, we ask whether 14.5-month-old infants realize that a naive agent looking at a misleading stimulus may falsely perceive it as one object when it is in fact another.

Developmental psychologists have long been interested in uncovering the early roots of adults' ability to attribute mental states to others. Much of this research has involved simple scenes in which an agent acts on objects in a single setting and has examined children's ability to reason about two kinds of internal states: motivational states, such as dispositions and goals, which specify the agent's motivation in the scene, and informational states, such as perceptions and beliefs, which specify the agent's information about the setting (e.g., Gergely, Nádasdy, Csibra, \& Bíró, 1995; Kuhlmeier, Wynn, \& Bloom, 2003; Leslie, 1994; Premack, 1990; Song, Baillargeon, \& Fisher, 2005; Woodward, 1998).

Experiments focusing on motivational states have revealed that even young infants can attribute dispositions and goals to others

Hyun-joo Song, Department of Psychology, Yonsei University, Seoul, Korea; Renée Baillargeon, Department of Psychology, University of Illinois.

This research was supported by a grant from Yonsei University to Hyun-joo Song (2006-1-0029) and by a grant from the National Institute of Child Health and Human Development (HD-021104) to Renée Baillargeon. We thank Peggy Miller and Sylvia Yuan for helpful suggestions, the staff of the Infant Cognition Laboratory at the University of Illinois for their help with the data collection, and the parents and infants who participated in the research.

Correspondence concerning this article should be addressed to Hyun-joo Song, Department of Psychology, Yonsei University, 134 Shinchon-dong Seodaemun-gu, Seoul, Korea 120-749. E-mail: hsong@yonsei.ac.kr (e.g., Csibra, 2008; Csibra, Gergely, Bíró, Koós, \& Brockbank, 1999; Hamlin, Wynn, \& Bloom, 2007; Johnson, Ok, \& Luo, 2007; Kamerawi, Kato, Kanda, Ishiguro, \& Hiraki, 2005; Luo \& Baillargeon, 2005; Song \& Baillargeon, 2007; Woodward, 1998). For example, after watching an agent repeatedly reach for Object A as opposed to Object B in a setting, 5-month-olds attribute to the agent a particular disposition, a preference for Object A over Object B. When the objects' positions are reversed, infants expect the agent to reach for Object $\mathrm{A}$ in its new position, and they look reliably longer if the agent reaches for Object B instead (Luo \& Baillargeon, 2005; Woodward, 1998).

In contrast, experiments focusing on informational states have revealed a striking developmental shift having to do with children's ability to attribute two different kinds of informational states to agents: reality-congruent and reality-incongruent states.

Reality-congruent informational states specify what accurate information an agent possesses or lacks about a setting, and they allow children to deal with situations where the agent's representation of the setting is incomplete: For example, the agent is ignorant about the presence or location of an object in the setting. Recent research indicates that by the end of the first year, infants keep track of what objects an agent can or cannot see and has or has not seen in a setting, and they interpret the agent's actions accordingly (e.g., Brooks \& Meltzoff, 2005; Caron, Kiel, Dayton, \& Butler, 2002; Liszkowski, Carpenter, Striano, \& Tomasello, 2006; Liszkowski, Carpenter, \& Tomasello, 2007; Luo \& Baillargeon, 2007; Luo \& Johnson, in press; Tomasello \& Haberl, 2003). Thus, 12.5-month-olds who watch an agent repeatedly reach for Object A over Object B do not attribute to the agent a preference for Object $\mathrm{A}$ if Object B is hidden from the agent by a screen; however, they do attribute such a preference if the agent is aware of Object B's presence behind the screen, because the agent saw it there earlier (Luo \& Baillargeon, 2007).

Reality-incongruent informational states specify what inaccurate information an agent possesses about a setting and allow children to deal with situations where the agent's representation of the setting is not merely incomplete but false: For example, the 
agent holds a false belief about the location or contents of an object, or the agent perceives a misleading stimulus as one object when it is in fact another. To reason correctly about the agent's actions in such situations, children cannot simply identify those aspects of the setting about which the agent is ignorant, as with reality-congruent states; rather, children must specify how the agent actually represents the setting. For example, if the agent believes that an object is hidden in Location A when it is in fact hidden in Location B, noting that the agent is ignorant about the object's current location is not sufficient to predict the agent's actions; to do so, children must specify that the agent believes the object is in Location A. To attribute a reality-incongruent state to an agent, children must thus be able to hold in mind two distinct versions of the setting: one that corresponds to reality (as they construe it) and one that corresponds to the agent's false representation. Until recently, it was generally assumed that this ability did not emerge until about 4 years of age (e.g., Flavell, 1988; Gopnik \& Wellman, 1994; Perner, 1995; Wellman, Cross, \& Watson, 2001; for exceptions, see Leslie, 1987, 2000; Premack \& Premack, 1995).

The evidence for young children's difficulty with realityincongruent informational states has come primarily from falsebelief and false-perception tasks (e.g., Gopnik \& Astington, 1988; Moore, Pure, \& Furrow, 1990; Perner, Leekam, \& Wimmer, 1987; Wimmer \& Perner, 1983). In a false-belief task (e.g., BaronCohen, Leslie, \& Frith, 1985), children listen to a story enacted with props: A first character hides a toy in Location A and leaves; while he or she is gone, a second character moves the toy to Location B. When asked where the first character will look for the toy, most 4-year-olds correctly point to Location A; in contrast, most 3-year-olds point to Location B, suggesting that they do not understand that the first character will hold a false belief about the toy's location. Similarly, in a false-perception task (e.g., Gopnik \& Astington, 1988), children explore a fake object, such as a sponge that looks like a rock. When asked how the object will appear to a naive agent, most 3-year-olds demonstrate no understanding that the agent will be misled by the object's appearance.

Evidence from novel false-belief tasks, designed to tap spontaneous rather than elicited responses, suggests that the ability to attribute reality-incongruent informational states may emerge earlier than previously thought (e.g., Clements \& Perner, 1994; Onishi \& Baillargeon, 2005; Song, Onishi, Baillargeon, \& Fisher, in press; Southgate, Senju, \& Csibra, 2007a; Surian, Caldi, \& Sperber, 2007). Some of these novel tasks used the violation-ofexpectation (VOE) method, which relies on infants' tendency to look longer at events that violate as opposed to confirm their expectations. For example, Onishi and Baillargeon (2005) gave 15 -month-olds familiarization trials in which an agent hid a toy in Location A as opposed to Location B. Next, the toy moved to Location B in the agent's absence. In the test trial, the agent returned and reached for either location. The infants who saw the agent reach for Location B looked reliably longer than those who saw the agent reach for Location A. This and other results suggested that the infants realized that, because the agent had not seen the toy move to Location $\mathrm{B}$, she still believed the toy to be in Location A; as a result, they expected the agent to reach for Location A and were surprised when she reached for Location B instead (we present alternative interpretations that have been offered for these findings in the Discussion section).
The present research sought new evidence that infants in the second year of life can reason about reality-incongruent informational states. To succeed at the novel false-belief tasks cited earlier, infants had to understand that the agent held a false belief about the location of a hidden object; to succeed at the novel falseperception task used here, infants had to understand that the agent formed a false perception of a visible object.

Participants were 14.5-month-olds, and they were tested with the VOE method. Because infants' limited knowledge made the use of fake objects impractical, we chose a different experimental approach: The agent first saw an object and later encountered a box with a part similar to a portion of the object protruding from under its lid. We reasoned that evidence that infants expected the agent to mistakenly perceive the part as belonging to the object would support the claim that the ability to attribute realityincongruent informational states is already present in the second year of life.

\section{Design}

The infants were assigned to a false- or a true-perception condition (see Figure 1). All infants received four familiarization trials, one box-orientation trial, and one test trial; each trial consisted of an initial and a final phase.

In the familiarization trials, a female agent sat at a window in the back wall of an apparatus and faced two toys: a cloth doll with blue woolen hair and a stuffed skunk. In the first two trials, each toy sat in front of a small mat, with the doll on the left and the skunk on the right; in the last two trials, the mats were replaced with shallow boxes, and the toys' locations were reversed. During the initial phase of each trial (which lasted about $18 \mathrm{~s}$ ), an experimenter's gloved hands reached into the apparatus through a window in the right wall, placed each toy on its mat or inside its shallow box, and then left. Next, the agent grasped the doll and then paused. During the final phase, the infants watched this paused scene until the trial ended. The familiarization trials served to establish that (a) a doll and a skunk were present in each trial; (b) the two toys could appear in different locations (left or right) and arrangements (on mats or inside boxes); and (c) the agent always reached for the doll, suggesting that she preferred it over the skunk.

In the box-orientation trial, the agent was either absent (her window was closed with two small doors; false-perception condition) or present (true-perception condition). Two tall boxes stood on the apparatus floor with their lids upside-down; the left box had a plain lid, and the right box had a tuft of blue hair similar to the doll's hair attached to its lid's interior surface. During the initial phase (which lasted about $26 \mathrm{~s}$ ), the gloved hands rotated the lid of the hair box five times and finally placed it upright on the box; the tuft of hair then hung between the two boxes. Next, the gloved hands performed the same actions on the lid of the plain box and then left. During the final phase, the infants watched this scene until the trial ended. The box-orientation trial served to establish that the hair box had a tuft of hair attached to its lid.

In the test trial, the doll sat in front of the plain box, and the skunk sat in front of the hair box. During the initial phase (which lasted about $28 \mathrm{~s}$ ), the gloved hands hid the doll inside the plain 
False-perception Condition

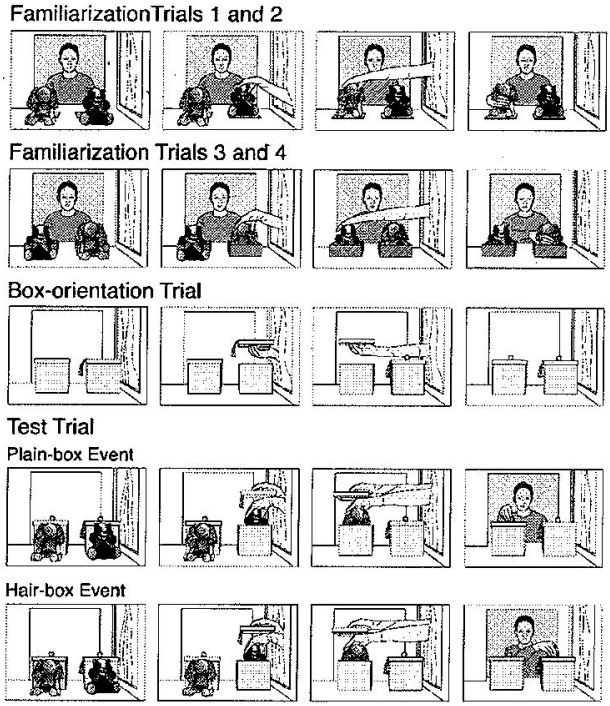

True-perception Condition

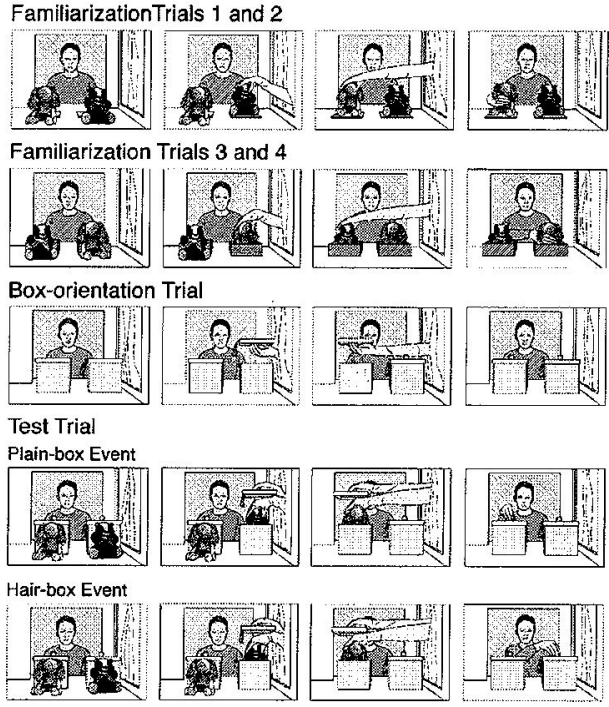

Figure 1. Familiarization, box-orientation, and test events shown in the false-perception (left panel) and true-perception (right panel) conditions of the doll experiment. In the false-perception condition, the agent was absent during the box-orientation trial and during the hiding of the doll and skunk in the test trial; in the true-perception condition, the agent was present throughout the trials. To help the agent and experimenter adhere to the events' second-by-second scripts, a metronome beat softly once per second. A camera mounted behind and next to the infant projected an image of the events onto a TV screen in a different part of the test room; a supervisor monitored the events to confirm that they followed the prescribed scripts. At the start of the first two familiarization trials, each toy sat on a dot centered $4.5 \mathrm{~cm}$ in front of a green mat; the two mats rested $9.5 \mathrm{~cm}$ apart, $14 \mathrm{~cm}$ in front of the back wall and $4 \mathrm{~cm}$ from the right wall. The agent sat at the window in the back wall of the apparatus, with her hands in her lap and her eyes focused on a neutral mark on the floor centered between the two mats. While acting on an object (e.g., reaching for and grasping the doll), the agent kept her eyes on the object; otherwise, she kept her eyes on the neutral mark and thus did not make eye contact with the infant. The mats were replaced with shallow red boxes in the next two familiarization trials and with tall yellow boxes in the box-orientation and test trials; the left yellow box had a plain lid, and the right yellow box had a tuft of blue hair similar to the doll's hair protruding from under its lid.

box, hid the skunk inside the hair box, and then left. In the true-perception condition, the agent was present during the hiding of the toys. In the false-perception condition, the agent was absent; after the gloved hands left, she opened the doors in her window. In both conditions, the agent then grasped the knob attached to the lid of the plain box (plain-box event) or the hair box (hair-box event) and paused. During the final phase, the infants watched this paused scene until the trial ended.

We reasoned that if the infants in the false-perception condition realized that the agent was likely (a) to mistakenly perceive the tuft of hair as a part of the doll and hence (b) to mistakenly conclude that the doll was hidden in the hair box and the skunk was hidden in the plain box, then they should expect the agent to reach for the hair box. The infants who saw the plain-box event should thus look reliably longer than those who saw the hair-box event. Conversely, the infants in the true-perception condition should expect the agent to reach for the plain box, where she had seen the doll being hidden. The infants who saw the hair-box event should thus look reliably longer than those who saw the plain-box event. ${ }^{1}$

Additional infants were tested in a skunk experiment identical to the doll experiment just described, except that the agent repeatedly reached for the skunk during the familiarization trials, suggesting

\footnotetext{
${ }^{1}$ Readers might wonder whether the box-orientation trial was necessary in either the false- or the true-perception condition: After all, the infantsand the agent in the true-perception condition-could see in the test trial, when the gloved hands hid the skunk in the hair box, that the tuft of hair was simply attached to the box's lid. Our concern (supported by pilot data) was that this brief glimpse of the box's lid might not be sufficient for the infants to adequately encode the tuft of hair, especially given that it came in the midst of a complex event sequence with a great deal of new information: Not only were new boxes used, but the infants also had to keep track of where each toy was hidden. We speculated that introducing the tuft of hair in a separate box-orientation trial might reduce the infants' information-processing load in the test trial and thus increase the likelihood of their success (for a similar approach, see, e.g., Onishi, Baillargeon, \& Leslie, 2007; Song et al., 2005). Would it have been possible in the true-perception condition to have the agent be absent for the boxorientation trial, as in the false-belief condition? As a first step, it seemed simpler to have the agent remain for all trials; however, future research could examine whether infants in the true-perception condition would still respond in the same manner if the agent was absent during the boxorientation trial (e.g., infants might require a separate introduction to the tuft of hair but might assume that the agent does not).
} 
that she preferred it over the doll. If the infants in the falseperception condition again realized that the agent was likely to conclude that the doll was hidden in the hair box and the skunk was hidden in the plain box, then they should expect the agent to reach for the plain box, and they should look reliably longer when she reached for the hair box instead. Conversely, the infants in the true-perception condition should expect the agent to reach for the hair box, where she had observed the skunk being hidden, and they should look reliably longer when she reached for the plain box instead. Opposite looking patterns were therefore predicted for the false- and true-perception conditions of the doll and skunk experiments, in a three-way interaction involving experiment, condition, and event.

\section{Method}

\section{Participants}

Participants were 48 full-term infants, 25 male and 23 female (ages 13 months and 25 days to 14 months and 29 days; $M=14$ months and 14 days). Another 16 infants were excluded because they were inattentive (6), active (3), fussy (2), or distracted (1), because they looked over 2.5 standard deviations from the mean of their condition during the test trial (3), or because they looked for the maximum time allowed during familiarization (1). Equal numbers of infants were assigned to the eight groups formed by crossing the experiment (doll or skunk), condition (false- or trueperception), and event (plain- or hair-box) factors.

Participants in the doll and skunk experiments (and in control experiments described in the Results section) were recruited primarily from purchased mailing lists and from birth announcements in the local newspaper. Parents were contacted by letters and follow-up phone calls; they were offered reimbursement for their transportation expenses but were not compensated for their participation. The racial and ethnic composition of the sample of infants tested in the present research was $81 \%$ Caucasian, $11 \%$ Asian (or mixed Asian and Caucasian), $6 \%$ Hispanic (or mixed Hispanic and Caucasian), and 2\% African American (or mixed African American and Caucasian). No information was collected on parents' education, occupation, or income.

\section{Apparatus}

The apparatus consisted of a wooden display booth $(124 \mathrm{~cm}$ high $\times 102 \mathrm{~cm}$ wide $\times 58.5 \mathrm{~cm}$ deep) mounted $78 \mathrm{~cm}$ above the floor of a brightly lit test room. The infant sat on a parent's lap and faced an opening $(46.5 \mathrm{~cm} \times 95 \mathrm{~cm})$ in the front of the apparatus; between trials, a muslin-covered frame $(59.5 \mathrm{~cm} \times 101.5 \mathrm{~cm})$ was lowered in front of this opening. The back and side walls of the apparatus were white, and the floor was white with pastel flowers.

The agent wore a blue shirt and sat behind a window $(50 \mathrm{~cm} \times$ $50 \mathrm{~cm}$ ) in the back wall of the apparatus; this window could be closed with two white doors. A muslin curtain behind the agent hid the test room. The experimenter wore long gold gloves and sat behind a window $(51 \mathrm{~cm} \times 38 \mathrm{~cm})$ in the right wall of the apparatus; this window was filled with a muslin fringe curtain.

The doll wore a green jumper and shoes and had blue woolen hair gathered in two pigtails, each $11.5 \mathrm{~cm}$ long; she sat with her legs straight out and was $17 \mathrm{~cm}$ high, $15.5 \mathrm{~cm}$ wide (widest point), and $11.5 \mathrm{~cm}$ deep (deepest point). The skunk had black and white fur, sported a pink bow around its neck, and was $15.5 \mathrm{~cm}$ high, 15 $\mathrm{cm}$ wide (widest point), and $11.5 \mathrm{~cm}$ deep (deepest point).

Across trials, the toys were placed on green mats (each 0.5 $\mathrm{cm} \times 17 \mathrm{~cm} \times 14 \mathrm{~cm}$ ), inside shallow red boxes (each $6 \mathrm{~cm} \times 17$ $\mathrm{cm} \times 14 \mathrm{~cm}$ ), or inside tall yellow boxes (each $16 \mathrm{~cm} \times 17 \mathrm{~cm} \times$ $14 \mathrm{~cm})$. Each tall box had a yellow lid $(2 \mathrm{~cm} \times 17.5 \mathrm{~cm} \times 14.5$ $\mathrm{cm})$ with a white interior and a round wooden knob $(3 \mathrm{~cm})$ centered on its top. The box on the right had a tuft of blue woolen hair $12 \mathrm{~cm}$ long attached at one end to the interior of its lid; when the lid was in place, about $7 \mathrm{~cm}$ of the tuft hung outside of the box on the left side.

\section{Procedure}

Two naive observers monitored each infant's looking behavior through peepholes in large cloth-covered frames on either side of the apparatus. Looking times during the initial and final phase of each trial were computed separately, using the primary observer's responses.

The infants were highly attentive during the initial phase of each trial: They looked for $17.5,17.7,17.9$, and $17.7 \mathrm{~s}$ during the 18-s initial phase of the four familiarization trials; they looked for $25.7 \mathrm{~s}$ during the 26-s initial phase of the box-orientation trial; and they looked for $27.0 \mathrm{~s}$ during the 28-s initial phase of the test trial.

The final phase of each trial ended when the infant (a) looked away for 2 consecutive seconds after having looked for at least 5 (familiarization and box-orientation trials) or 6 (test trial) cumulative seconds, ${ }^{2}$ or (b) looked for 60 (familiarization trials) or 30 (box-orientation and test trials) cumulative seconds without looking away for 2 consecutive seconds. Interobserver agreement during the final phase of each trial averaged $95 \%$ per trial per infant. Preliminary analyses of the test data revealed no significant interaction involving sex; the data were therefore collapsed across sex in subsequent analyses.

\section{Results}

We analyzed the infants' looking times during the final phase of the test trial with a $2 \times 2 \times 2$ analysis of variance with experiment (doll or skunk), condition (false- or true-perception), and event (plain- or hair-box) as between-subjects variables (see Figure 2). The only significant effect was the predicted Experiment $\times$ Condition $\times$ Event interaction, $F(1,40)=34.44, p<.0001, \eta_{\mathrm{p}}^{2}=.46$. Planned comparisons for the doll experiment revealed that in the

\footnotetext{
${ }^{2}$ Readers might wonder why a 5- or 6-s minimum looking time was required in the final phase of the familiarization, box-orientation, and test trials: Because no event occurred during this phase (the infants simply watched a paused scene), why not use a short, 1- or 2-s, minimum looking time? In prior experiments on physical or psychological reasoning in which VOE tasks with paused scenes were used, we found that infants sometimes performed better with a slightly longer minimum looking time (e.g., 4 to $7 \mathrm{~s}$ ), which gave them more time to process the information presented in the initial phase of the trial (e.g., Luo \& Baillargeon, 2005, 2007; Song et al., in press; Wang \& Baillargeon, 2005). The specific minimum looking time used in each type of trial was established through piloting; here because the test events differed from the previous events in several respects (e.g., the toys were fully hidden), a slightly longer minimum looking time seemed appropriate.
} 
Doll Experiment

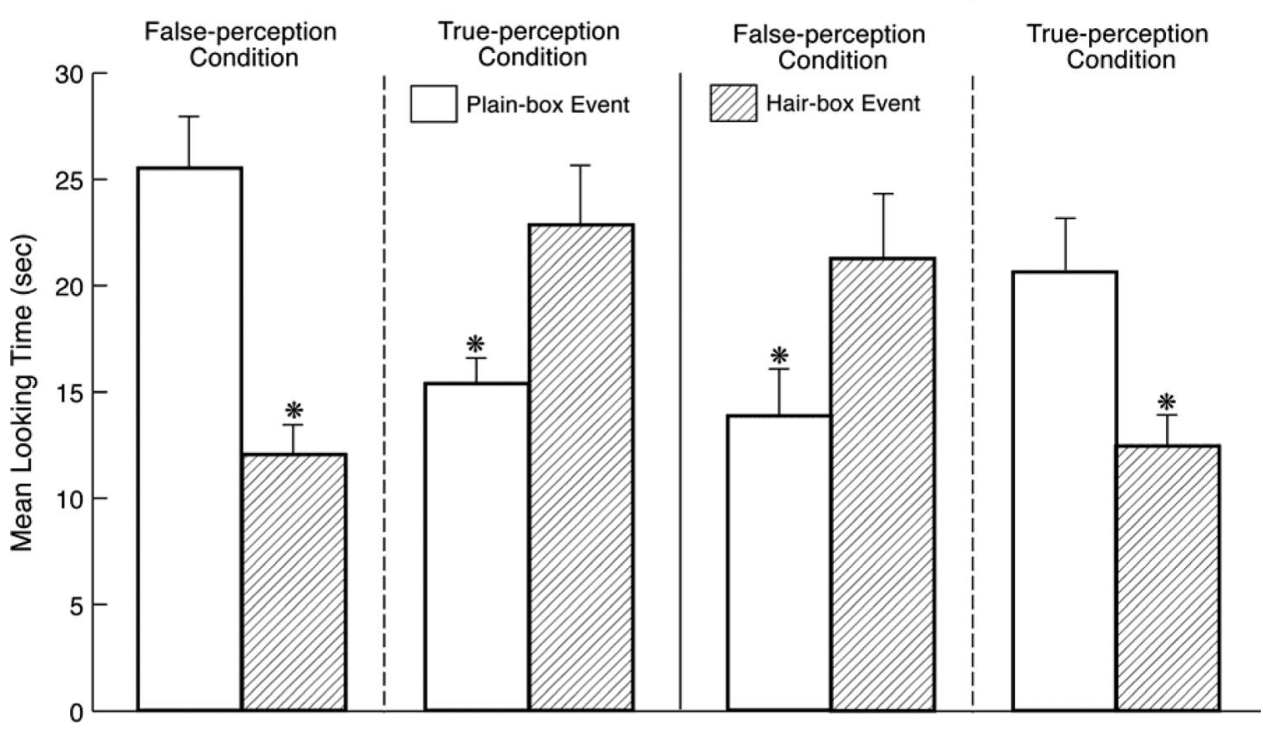

Figure 2. Mean looking times of the infants in the false- and true-perception conditions of the doll and skunk experiments during the final phase of the test trial. Within each condition, half the infants saw the plain-box event, and half saw the hair-box event. Asterisks indicate significant differences $(p<.05$ or better). Error bars represent standard errors.

false-perception condition the infants who saw the plain-box event looked reliably longer than those who saw the hair-box event, $F(1$, $40)=18.07, p<.00025$, Cohen's $d=2.71$, whereas in the true-perception condition the infants showed the reverse pattern, $F(1,40)=5.58, p<.025, d=1.38$. Planned comparisons for the skunk experiment revealed that in the false-perception condition the infants who saw the hair-box event looked reliably longer than those who saw the plain-box event, $F(1,40)=6.43, p<.025, d=$ 1.22 , whereas in the true-perception condition this pattern was again reversed, $F(1,40)=6.69, p<.025, d=1.70$. Analyses of the familiarization and box-orientation trials revealed no three-way interaction, both $F \mathrm{~s}<2.15, p \mathrm{~s}>.15$.

The test data were also subjected to an analysis of covariance with the infants' average looking times during the familiarization trials and looking times during the box-orientation trial as covariates. The Experiment $\times$ Condition $\times$ Event interaction was again significant, $F(1,38)=37.76, p<.0001, \eta_{\mathrm{p}}^{2}=.50$, and planned comparisons yielded the same results as before: for the doll/falseperception condition, $F(1,38)=19.49, p<.0001, d=2.76$; for the doll/true-perception condition, $F(1,38)=8.06, p<.01, d=$ 1.63; for the skunk/false-perception condition, $F(1,38)=7.90$, $p<.01, d=1.33$; for the skunk/true-perception condition, $F(1$, $38)=6.89, p<.025, d=1.68$.

To confirm the results of the false-perception conditions in the doll and skunk experiments and to rule out the possibility that the infants in these conditions simply expected the agent to search for her preferred toy in the same left or right location as in the last two familiarization trials, additional infants were tested with the same procedure as in these conditions, with one exception: The locations of the doll and skunk were reversed in the four familiarization trials. Participants were 14 infants, 7 male and 7 female (ages 14 months and 1 day to 14 months and 25 days; $M=14$ months and
18 days). Another 7 infants were excluded because they were fussy (2), distracted (2), or looked over 2.5 standard deviations from the mean of their condition during the test trial (3). Half the infants were assigned to the doll experiment and half to the skunk experiment; within each experiment, 4 infants saw the plain-box event and 3 saw the hair-box event. The predicted Experiment $\times$ Event interaction was obtained in an analysis of variance, $F(1,10)=$ $8.22, p<.025, \eta_{\mathrm{p}}^{2}=.45$, and in an analysis of covariance, $F(1$, $8)=27.32, p<.01, \eta_{\mathrm{p}}^{2}=.77$. Like the infants in the original false-perception conditions, these infants expected the agent to search for the doll in the hair box and for the skunk in the plain box, and they looked longer when she did not.

\section{Discussion}

The present findings suggest three conclusions. First, the infants attributed to the agent a preference for whichever toy she repeatedly reached for during the familiarization trials, and they expected her to maintain this preference during the test trial. Second, the infants expected the agent who watched the doll and skunk being hidden to correctly search for her preferred toy. Third, the infants expected the agent who did not see the doll and skunk being hidden (a) to mistakenly perceive the tuft of hair as belonging to the doll, (b) to mistakenly conclude that the doll was hidden in the hair box and the skunk was hidden in the plain box, and hence (c) to search for her preferred toy accordingly. These last results indicate that by 14.5 months of age, infants can keep in mind two distinct versions of an object: one that corresponds to reality and one that corresponds to an agent's false perception. The present research thus indicates that infants in the second year of life can reason about false perceptions as well as false beliefs (e.g., Onishi \& Baillargeon, 2005; Song et al., in press; Surian et al., 2007) and, 
as such, provides new evidence that infants this age can attribute reality-incongruent informational states to agents.

The present results also suggest that 14.5-month-olds can take into account multiple internal states of agents when reasoning about their actions. To succeed, the infants in the false-perception conditions had to attribute to the agent a particular disposition during the familiarization trials - a preference for the toy she consistently reached for-and they had to assume that this preference would lead her to form the goal in the test trial of searching for her preferred toy. The infants also had to consider the agent's knowledge of the setting in the test trial: They had to attribute to the agent not only the ability to detect the tall boxes and tuft of hair, but also the ability to infer that the doll and skunk were likely to both be present, as in the preceding trials, and to be hidden in the boxes. Finally, the infants had to reason that the agent's false perception of the tuft of hair as a part of the doll would lead her to hold false beliefs about the locations of the doll and skunk.

Could weaker interpretations be offered for our results? As a starting point, consider three alternative interpretations that have been offered for the results of Onishi and Baillargeon (2005), described in the introductory section. One interpretation was that the infants formed a three-way association among the agent, the toy, and the location where the toy became hidden and that they looked reliably longer when the test trial deviated from this association (Perner \& Ruffman, 2005). Another interpretation was that the infants came to the task with a learned behavioral rule that agents searching for a hidden object typically look for it where they saw it disappear (Onishi \& Baillargeon, 2005; Perner \& Ruffman, 2005). Yet another interpretation was that the infants possessed a general expectation that ignorance leads to error: Thus, because the agent was ignorant about the toy's current location, they expected her to search for it in the wrong location (Southgate et al., 2007a).

The first two interpretations do not apply to the present research. To see why, consider in particular the false-perception condition of the skunk experiment. Because the agent did not see the plain and hair boxes until the test trial and because she did not witness the hiding of the skunk in the plain box, the infants could not have formed a three-way association among the agent, the skunk, and the plain box, nor could they have predicted where the agent would search for the skunk on the basis of where she saw it disappear.

The third interpretation does apply to the present findings: Because the agent was ignorant about her preferred toy's location, perhaps the infants expected her to search for it in the wrong box and were surprised when she reached for the correct box instead. However, recent evidence does not support the notion that infants expect ignorance to lead to error. First, VOE tasks have shown that when an agent is ignorant about whether a toy is in Location A or Location B, infants do not expect her to go to the wrong location; rather, they have no expectation about which location she will search (e.g., He \& Baillargeon, 2007; Scott \& Baillargeon, in press; Scott, Song, Baillargeon, \& Leslie, 2007). Second, anticipatory-looking tasks have shown that when an agent falsely believes a toy is in Location A as opposed to Location B and when the toy has in fact been removed from the situation so that both locations are wrong, infants do not look at either location randomly; rather, they correctly anticipate that the agent will search for the toy at Location A (Southgate et al., 2007a; Southgate, Senju, \& Csibra, 2007b).
In summary, the present results demonstrate that infants in the second year of life can reason about agents' false perceptions as well as false beliefs (e.g., Onishi \& Baillargeon, 2005; Scott \& Baillargeon, in press; Song et al., in press; Surian et al., 2007). As such, the results support the view that early psychological reasoning depends on a specialized computational system, which provides infants with a skeletal causal framework for interpreting intentional actions (e.g., Gergely \& Csibra, 2003; Leslie, 1994; Luo \& Baillargeon, 2007; Premack \& Premack, 1995; Scott \& Baillargeon, in press; Song et al., in press). From this theoretical stance, what developmental questions might one explore with respect to infants' ability to attribute reality-incongruent informational states? First, one might ask how early this ability emerges (preliminary results suggest that it is already present by the end of the first year; He \& Baillargeon, 2007); whether it emerges at the same time as, or only after, the ability to attribute reality-congruent states; and whether different computational subsystems underlie these two abilities (e.g., Leslie, 1994, 2000; Scott \& Baillargeon, in press; Song et al., in press). Second, one might examine developments in infants' ability to attribute different kinds of realityincongruent states; in particular, does infants' understanding of pretend beliefs, which emerges in the second year, build on their understanding of false beliefs (e.g., Leslie, 1987; Onishi et al., 2007)? The answers to these questions should yield important insights into the early course of human psychological reasoning.

\section{References}

Baron-Cohen, S., Leslie, A. M., \& Frith, U. (1985). Does the autistic child have a "theory of mind"? Cognition, 21, 37-46.

Brooks, R., \& Meltzoff, A. N. (2005). The development of gaze following and its relation to language. Developmental Science, 8, 535-543.

Caron, A. J., Kiel, E. J., Dayton, M., \& Butler, S. (2002). Comprehension of the referential intent of looking and pointing between 12 and 15 months. Journal of Cognition and Development, 3, 445-464.

Clements, W. A., \& Perner, J. (1994). Implicit understanding of belief. Cognitive Development, 9, 377-395.

Csibra, G. (2008). Goal attribution to inanimate agents by 6.5 -month-old infants. Cognition, 107, 705-717.

Csibra, G., Gergely, G., Bíró, S., Koós, O., \& Brockbank, M. (1999). Goal attribution without agency cues: The perception of 'pure reason' in infancy. Cognition, 72, 237-267.

Flavell, J. H. (1988). The development of children's knowledge about the mind: From cognitive connections to mental representations. In J. W. Astington, P. L. Harris, \& D. R. Olson (Eds.), Developing theories of mind (pp. 244-267). New York: Cambridge University Press.

Gergely, G., \& Csibra, G. (2003). Teleological reasoning in infancy: The naive theory of rational action. Trends in Cognitive Sciences, 7, 287292.

Gergely, G., Nádasdy, Z., Csibra, G., \& Bíró, S. (1995). Taking the intentional stance at 12 months of age. Cognition, 56, 165-193.

Gopnik, A., \& Astington, J. W. (1988). Children's understanding of representational change and its relation to the understanding of false belief and the appearance-reality distinction. Child Development, 59, 26-37.

Gopnik, A., \& Wellman, A. (1994). The "theory theory". In L. Hirschfield \& S. Gelman (Eds.), Domain specificity in culture and cognition (pp. 257-293). New York: Cambridge University Press.

Hamlin, J. K., Wynn, K., \& Bloom, P. (2007). Social evaluation by preverbal infants. Nature, 450, 557-559.

He, Z., \& Baillargeon, R. (2007, March). Understanding of false belief in 11-month-old infants. Paper presented at the biennial meeting of the Society for Research in Child Development, Boston. 
Johnson, S. C., Ok, S., \& Luo, Y. (2007). The attribution of attention: 9-month-olds' interpretation of gaze as goal-directed action. Developmental Science, 10, 530-537.

Kamerawi, K., Kato, M., Kanda, T., Ishiguro, H., \& Hiraki, K. (2005). Six-and-a-half-month-old children positively attribute goals to human action and to humanoid-robot motion. Cognitive Development, 20, 303320 .

Kuhlmeier, V. A., Wynn, K., \& Bloom, P. (2003). Attribution of dispositional states by 12-month-olds. Psychological Science, 14, 402-408.

Leslie, A. M. (1987). Pretense and representation: The origins of 'theory of mind'. Psychological Review, 94, 412-426.

Leslie, A. M. (1994). ToMM, ToBy, and Agency: Core architecture and domain specificity. In L. Hirschfeld \& S. Gelman (Eds.), Mapping the mind: Domain specificity in cognition and culture (pp. 119-148). New York: Cambridge University Press.

Leslie, A. M. (2000). How to acquire a 'representational theory of mind'. In D. Sperber (Ed.), Metarepresentations: A multidisciplinary perspective (pp. 197-223). Oxford: Oxford University Press.

Liszkowski, U., Carpenter, M., Striano, T., \& Tomasello, M. (2006). 12and 18-month-olds point to provide information to others. Journal of Cognition and Development, 7, 173-187.

Liszkowski, U., Carpenter, M., \& Tomasello, M. (2007). Pointing out new news, old news, and absent referents at 12 months of age. Developmental Science, 10, F1-F7.

Luo, Y., \& Baillargeon, R. (2005). Can a self-propelled box have a goal? Psychological reasoning in 5-month-old infants. Psychological Science, 16, 601-608.

Luo, Y., \& Baillargeon, R. (2007). Do 12.5-month-old infants consider what objects others can see when interpreting their actions? Cognition, 105, 489-512.

Luo, Y., \& Johnson, S. C. (in press). Recognizing the role of perception in action at 6 months. Developmental Science.

Moore, C., Pure, K., \& Furrow, D. (1990). Children's understanding of the modal expression of speaker certainty and uncertainty and its relation to the development of a representational theory of mind. Child Development, 61, 722-730.

Onishi, K. H., \& Baillargeon, R. (2005, April 8). Do 15-month-old infants understand false beliefs? Science, 308, 255-258.

Onishi, K. H., Baillargeon, R., \& Leslie, A. M. (2007). 15-month-old infants detect violations in pretend scenarios. Acta Psychologica, 124, $106-128$.

Perner, J. (1995). The many faces of belief: Reflections on Fodor's and the child's theory of mind. Cognition, 57, 241-269.

Perner, J., Leekam, S. R., \& Wimmer, H. (1987). Three-year-olds' difficulty with false belief: The case for a conceptual deficit. British Journal of Developmental Psychology, 5, 125-137.

Perner, J., \& Ruffman, T. (2005, April 8). Infants' insight into the mind: How deep? Science, 308, 214-216.
Premack, D. (1990). The infant's theory of self-propelled objects. Cognition, 36, 1-16.

Premack, D., \& Premack, A. J. (1995). Origins of human social competence. In M. S. Gazzaniga (Ed.), The cognitive neurosciences (pp. 205-218). Cambridge, MA: MIT Press.

Scott, R. M., \& Baillargeon, R. (in press). Which penguin is this? Attributing false beliefs about object identity at 18 months. Child Development.

Scott, R. M., Song, H., Baillargeon, R., \& Leslie, A. M. (2007, March). 18.5-month-old infants attribute to others false beliefs about objects' internal properties. Paper presented at the biennial meeting of the Society for Research in Child Development, Boston.

Song, H., \& Baillargeon, R. (2007). Can 9.5-month-old infants attribute to an actor a disposition to perform a particular action on objects? Acta Psychologica, 124, 79-105.

Song, H., Baillargeon, R., \& Fisher, C. (2005). Can infants attribute to an agent a disposition to perform a particular action? Cognition, 98, B45B55.

Song, H., Onishi, K. H., Baillargeon, R., \& Fisher, C. (in press). Can an agent's false belief be corrected through an appropriate communication? Psychological reasoning in 18.5-month-old infants. Cognition.

Southgate, V., Senju, A., \& Csibra, G. (2007a). Action anticipation through attribution of false belief by two-year-olds. Psychological Science, 18, 587-592.

Southgate, V., Senju, A., \& Csibra, G. (2007b, March). 24-month-olds expect others to act in accord with a false belief. Paper presented at the biennial meeting of the Society for Research in Child Development, Boston.

Surian, L., Caldi, S., \& Sperber, D. (2007). Attribution of beliefs to 13-month-old infants. Psychological Science, 18, 580-586.

Tomasello, M., \& Haberl, K. (2003). Understanding attention: 12- and 18 -month-olds know what is new for other persons. Developmental Psychology, 39, 906-912.

Wang, S., \& Baillargeon, R. (2005). Inducing infants to detect a physical violation in a single trial. Psychological Science, 16, 542-549.

Wellman, H. M., Cross, D., \& Watson, J. (2001). Meta-analysis of theoryof-mind development: The truth about false belief. Child Development, $72,655-684$.

Wimmer, H., \& Perner, J. (1983). Beliefs about beliefs: Representation and constraining function of wrong beliefs in young children's understanding of deception. Cognition, 13, 103-128.

Woodward, A. L. (1998). Infants selectively encode the goal object of an actor's reach. Cognition, 69, 1-34.

Received August 20, 2007

Revision received November 26, 2007

Accepted April 8, 2008 